\title{
BMJ Open Clarifying the learning experiences of healthcare professionals with in situ and off-site simulation-based medical education: a qualitative study
}

\author{
Jette Led Sørensen, ${ }^{1}$ Laura Emdal Navne, ${ }^{2}$ Helle Max Martin, ${ }^{2}$ Bent Ottesen, ${ }^{1}$ \\ Charlotte Krebs Albrecthsen, ${ }^{3}$ Berit Woetmann Pedersen, ${ }^{4}$ Hanne Kjærgaard, ${ }^{5}$ \\ Cees van der Vleuten ${ }^{6}$
}

To cite: Sørensen JL, Navne LE, Martin HM, et al. Clarifying the learning experiences of healthcare professionals with in situ and off-site simulation-based medical education: a qualitative study. BMJ Open 2015;5:e008345.

doi:10.1136/bmjopen-2015008345

- Prepublication history for this paper is available online. To view these files please visit the journal online (http://dx.doi.org/10.1136/ bmjopen-2015-008345).

Received 28 March 2015 Revised 14 July 2015 Accepted 24 July 2015

\section{SLinked}

- http://dx.doi.org/10.1136/ bmjopen-2015-008344

CrossMark

For numbered affiliations see end of article.

Correspondence to Jette Led Sørensen; jette.led.soerensen@regionh.dk

\section{ABSTRACT}

Objective: To examine how the setting in in situ simulation (ISS) and off-site simulation (OSS) in simulation-based medical education affects the perceptions and learning experience of healthcare professionals.

Design: Qualitative study using focus groups and content analysis.

Participants: Twenty-five healthcare professionals (obstetricians, midwives, auxiliary nurses, anaesthesiologists, a nurse anaesthetist and operating theatre nurse) participated in four focus groups and were recruited due to their exposure to either ISS or OSS in multidisciplinary obstetric emergencies in a randomised trial.

Setting: Departments of obstetrics and anaesthesia, Rigshospitalet, Copenhagen, Denmark.

Results: Initially participants preferred ISS, but this changed after the training when the simulation site became of less importance. There was a strong preference for simulation in authentic roles. These perceptions were independent of the ISS or OSS setting. Several positive and negative factors in simulation were identified, but these had no relation to the simulation setting. Participants from ISS and OSS generated a better understanding of and collaboration with the various health professionals. They also provided individual and team reflections on learning. ISS participants described more experiences that would involve organisational changes than the OSS participants did.

Conclusions: Many psychological and sociological aspects related to the authenticity of the learning experience are important in simulation, but the physical setting of the simulation as an ISS and OSS is the least important. Based on these focus groups OSS can be used provided that all other authenticity elements are taken into consideration and respected. The only difference was that ISS had an organisational impact and ISS participants talked more about issues that would involve practical organisational changes. ISS and OSS participants did, however, go through similar individual and team learning experiences.

\section{Strengths and limitations of this study}

- In situ simulation is fairly new and involves conducting simulations in the actual patient care unit, and based on the much-discussed topic of learning in context, in situ simulation is expected to increase fidelity and thereby learning. We had been unable to identify any qualitative studies exploring participant experiences of in situ versus off-site simulation (ie, simulation in training rooms).

- Based on findings from these focus groups the simulation settings in situ and off-site had the same effect on individual and team learning. In situ simulation had more organisational impact and provided more information for practical organisational changes than off-site simulation.

- Conclusions from the present focus groups indicated that healthcare professionals think that the physical context and physical fidelity of ISS and OSS were not the most important aspects for learning provided other psychological and sociological authenticity elements were respected. The participants in the focus groups highlighted the importance of participating in authentic teams in their own roles as healthcare professionals. This emerged in the focus groups as participants reflected on previous negative experiences of simulation in other professional roles.

- The findings from the focus groups in this study show that staff in obstetrics and anaesthesiology appeared to be more familiar with working in different places, which they saw as an important skill, but we cannot say whether study findings are transferable to other groups of healthcare professionals working in medical areas with less emergency work or health-care professionals without simulation experience.

- A limitation was the composition of the focus groups, which did not entirely mirror the distribution of healthcare professionals during the clinical work, and some groups were under-represented. 


\section{INTRODUCTION}

Simulation-based medical education is an important training modality for training skills, teams and how to perform in emergency situations. ${ }^{1-4}$ If emergencies are rare and hence can be difficult to learn about in real life, simulation-based medical education is warranted, for instance in obstetric emergencies. ${ }^{5}$ Simulation-based medical education involves "devices, trained persons, lifelike virtual environments, and contrived social situations that mimic problems, events, or conditions that arise in professional encounters". ${ }^{4}$ There are many unanswered questions as to how simulation-based medical education is best conducted, one of which concerns the fidelity of the setting. An unresolved issue is how in situ simulation (ISS) versus off-site simulation (OSS) affects learning. ISS involves simulation-based medical education in the actual patient care unit. ${ }^{6}{ }^{7}$ OSS, on the other hand, entails training in facilities outside the patient care unit. ISS is believed to increase fidelity and thereby learning because it takes place in the clinical setting. ${ }^{7-9}$ In a classic sense fidelity refers to the degree of faithfulness that exists between two entities, and these entities are fundamental for the transfer of simulation-based medical education and performance in the clinical settings. ${ }^{10}$ The rationale behind this idea on the authenticity of simulation is the traditional assumption that the closer the learning context is to the context of practice, the better the learning and situativity theory argues that knowledge, thinking and learning are situated in experience. ${ }^{1-15}$ Therefore, ISS is believed to increase learning because it takes place in the clinical setting, where the learning context is more similar to the context of practice.

We conducted a randomised controlled trial to reveal whether ISS was superior in facilitating learning compared to OSS. ${ }^{16}$ We concluded that participant perception of the authenticity of ISS and OSS differed significantly but did not find any differences between knowledge, safety attitudes, motivation, stress, perceptions of the simulation and team performance. ${ }^{16}$ We were unable to identify any qualitative studies exploring how participants experience differences in the simulation setting and found that studies clarifying participants' experiences were of relevance. ${ }^{17}$ Consequently we determined that carrying out qualitative research in combination with the randomised controlled trial, which involved a complex intervention, would provide deeper insight into the learning experience of healthcare professionals participating in ISS and OSS. ${ }^{18}$

This study attempts to shed light on the general assumption that context and fidelity are a determinant for how different kinds of simulation-based medical education are experienced and to determine the veracity of the common assumption that ISS is a more effective learning tool than OSS. ${ }^{8}$ The research question was: How does the setting in simulation-based medical education (OSS or ISS) affect the perceptions and learning experience of healthcare professionals?
METHOD

\section{Design}

We chose to do a qualitative study using focus groups, deeming this to be an appropriate method with regard to the research question. Focus groups, which can be defined as "a form of group interview that capitalises on communication between research participants in order to generate data", ${ }^{19}$ are useful for gathering information about the points of view of different participants and can be used to explore and explain phenomena. ${ }^{20}$ We also wanted to examine data from the randomised controlled trial more closely ${ }^{16}$ and using focus groups is described as a valuable way of further analysing and interpreting data subsequently. ${ }^{18-20}$ The focus groups were conducted based on criteria in the literature. ${ }^{19} 20-24$

\section{Participant selection and intervention before the focus groups}

Prior to the present qualitative study a randomised trial $^{16}$ was conducted that recruited individuals from among 265 healthcare professionals working shifts on a labour ward. After giving written informed consent, randomisation was performed by the Copenhagen Trial Unit using a computer-generated allocation sequence concealed to the investigators. The randomisation was conducted in two steps, first, 1:1 to the ISS or the OSS group, then randomisation into 10 teams for either the ISS or OSS. Based on a power calculation 100 participants were randomised, and of these 97 participated in the randomised controlled trial. ${ }^{16}$

The focus group participants, recruited from among 97 healthcare professionals enrolled in an randomised controlled trial, comprised consultant and trainee obstetricians, midwives, consultant and trainee anaesthesiologists, auxiliary nurses, operating theatre nurses and nurse anaesthetists. ${ }^{16}$ The trial included two multidisciplinary simulation cases conducted using ISS or OSS: an emergency caesarean section and the management of postpartum haemorrhage. A simulated patient was given instructions and then acted as the patient in the real labour room (ISS) and in the simulated labour room (OSS). When the simulation was transferred to the operating theatre, a full-scale birthing simulator (SimMom) was the patient in the real operating theatre (ISS) and in the simulated operating theatre (OSS). The simulated emergency scenarios were designed to allow standardised training in both the ISS and OSS groups. ${ }^{16}$ The instructors running the simulation scenarios also carried out the debriefing sessions. ${ }^{25}$

\section{Recruitment and composition of the focus groups}

Eligible participants were informed by email and a personal letter. If they agreed to participate they were contacted by the principal investigator (JLS) and enrolled after informed written consent.

Only very few minor conflicts occurred during the randomised controlled trial ${ }^{16}$ and they did not involve anxiety or power dominance, indicating that using homogenous focus groups was not a necessity. Hence we 
also determined that the participants would feel comfortable in multidisciplinary focus groups. We also expected heterogeneous groups to add to the richness of data due to the process of co-construction. All four groups were to comprise individuals who had participated in ISS and OSS based on the assumption that this would add to the co-construction process. In accordance with recommendations in the literature ${ }^{20}$ each focus group was limited to $6-8$ participants.

\section{Moderators and conduction of the focus groups}

Two anthropologists (LEN, HMM) with comprehensive experience in moderating and analysing data from focus groups led the focus groups. They did not have any experience with obstetric-anaesthesia emergencies or simulation-based medical education. The principal investigator (JLS), who is an experienced obstetrician and an expert in simulation, introduced the moderators to the randomised controlled trial. ${ }^{16}$ LEN observed an ISS training day and part of an OSS day. In addition to viewing videos on ISS and OSS, both moderators observed clinical work in the departments of obstetrics and anaesthesia for a total of $28 \mathrm{~h}$. Neither moderators had any professional connection to the participants and did not know them personally.

The four focus groups, scheduled to begin immediately after end of the randomised controlled trial, ${ }^{16}$ lasted $105 \mathrm{~min}$ and took place in the afternoon in a quiet room located in the same building as the labour ward and the operating theatre but on a different floor. Participant remuneration was the equivalent of the participants' normal salary per hour.

Scheduled to come on a specific day, participants were welcomed on arrival by the principal investigator (JLS) or one of the midwives responsible for doing simulations. After briefly introducing the participants to the moderators, the principal investigator or midwife would leave the room.

The moderators were provided with the names of the participants in the focus groups and some of their baseline characteristics based on information from the randomised controlled trial. ${ }^{16}$

\section{Interview guide}

The interview guide (box 1) was based on previous experience, the anthropologists' observations of clinical work and OSS and ISS, and the literature. ${ }^{1-3} 8$ 26-28

\section{Data capture, coding and analysis of qualitative data}

Conventional content analysis, a method used for the subjective interpretation of written data through a classification process of coding and identifying themes or patterns, was used to study the focus group data. ${ }^{29-32}$ The method involves repeatedly reading and discussing the text to identify units of meaning and codes, followed by a step that entails repeatedly analysing the data and condensing it into themes. ${ }^{29-31}$ The analytical approach

\section{Box 1 Interview guide for the focus group}

What were your expectations concerning what you would learn during the simulation (ISS/OSS)? Were these expectations met?

- What was of most importance for your learning in the simulation (ISS/OSS)? What elements of the simulation were important?

- To what degree did you find the simulation (ISS/OSS) realistic/ authentic? What made the simulation (ISS/OSS) realistic and unrealistic?

- Was it possible to identify yourself with the simulation (ISS/ OSS)? Examples?

- Did you find it important for your learning that the simulation (ISS/OSS) was realistic/authentic? To what degree and why?

- Which elements contributed to making the simulation (ISS/ OSS) authentic/realistic? Perhaps compare your experience with previous experiences with simulation?

- Do you think that participating in the simulation (ISS/OSS) has influenced your clinical work and daily routines? Examples?

- How does, in your experience, learning through simulationbased training differ from and benefit you compared to daily clinical learning?

- Do you think that the ISS/OSS setting influenced your level of stress and anxiety?

- Do you think that the ISS/OSS setting influenced the cooperation and communication in your simulation team?

- How did you learn about roles and responsibility in the simulation? Were you influenced by the ISS/OSS setting?

Other suggested elements of importance in the focus groups

- The rooms

- The time spent on the simulation

- Placement and organisation of physical objects

- ounds

- Technical equipment

- Patient surrogate or the actress

- Manikin, for example, SimMom

- Participants' clothing

- Authentic roles in the simulation teams

- Simulation with colleagues from own workplace

used was mainly deductive and the transcribed text was analysed as manifest content. ${ }^{20} 3031$

The data generated in the focus groups were audio recorded and transcribed verbatim and the moderators also took field notes. NVivo10 was used for analysis. The transcription was primarily coded by the two moderators. The interview guide provided an initial structure for identifying units of meaning. The text was then reread and analysed to derive unanticipated units of meaning. The next step involved recoding and dividing the material into ISS and OSS to identify trends related to the simulation setting. The principal investigator (JLS) independently interpreted the data, after which the three authors (LEN, HMM, JLS) discussed, reread and validated the interpretations. The themes then underwent a selection process. The initial transcripts from the four focus groups were also read by CKA and BWP, both of whom are experienced clinicians and work with simulation. The 
purpose of their involvement was to integrate their interpretations into the themes. Finally, the transcripts were reread to identify crosscutting themes and perspectives. The participants did not receive a copy of the transcripts or the quotations taken from them.

\section{RESULTS}

\section{Sample characteristics and composition of focus groups}

We recruited 31 healthcare professionals, but three of them could not participate at the scheduled time and three others cancelled at the last minute. Every effort was made to meet the principles of composition of the focus groups described above. The final number of participants was 25 (table 1). The moderators described the group dynamics in the four focus groups as good and did not experience any tensions between participants. The moderators and principal investigator discussed data saturation and concluded it was achieved.

\section{Units of meaning and identification of themes}

The text was analysed and units of meaning were identified (box 2). The overall research question addressed the influence of setting (OSS or ISS) on what the participants experienced, which provided an overarching structure for establishing the following six themes and subthemes (box 3).

\section{Theme 1: initial participant expectations for in situ and} off-site simulation

When asked about their expectations in the beginning participants predominantly responded that prior to participating in the randomised controlled trial intervention they had a preconceived preference for participating in ISS because they believed that ISS better matched reality and assumed that this would affect their ability to involve themselves. They also thought that ISS would enhance their ability to transfer learning to everyday practice. An initial preference for ISS was visible in the four focus groups, but as discussion progressed this preference waned and the amount of value participants put on an ISS setting as a crucial factor for their experience of learning in simulation shifted as other factors were deemed as more crucial (box 4, quotations 1-3).

\section{Theme 2: importance of simulation site}

Some OSS participants mentioned that being in an unfamiliar location had some unexpected positive effects, as it forced the participants to practice their ability to adapt to new places and people, which several participants emphasised as an important skill in clinical practice and in emergencies. Both ISS and OSS participants experienced practical challenges or barriers, but argued that this could produce learning outcomes of their own. Some argued that the OSS setting in a small room, where things were organised differently and not in their normal place, forced them to see their own routines from the outside. This was considered positive even though it increased the risk of failing to follow normal procedures (box 5, quotation 1 and 2).

The discussions about ISS and OSS seemed to vary between healthcare professional groups. Auxiliary and operating theatre nurses appeared to have a greater need to have equipment in the right place. They felt that unfamiliarity with where items were located meant they had trouble finding, for example medicine, thus taking their attention away from their main tasks: teamwork and communication. Since the professional groups were not well represented in all the focus groups the differences between them can only be viewed as a trend (box 5, quotation 2).

\section{Theme 3: preference for simulation in authentic roles in own} workplace

The participants emphasised a heavy preference for simulation in authentic roles in their own professional groups. Some participants created a hierarchy of important factors in the simulation, prioritising individuals before location and ranking realistic teamwork ahead of a realistic location. Describing negative prior experiences with simulation in professional roles other than their own, they argued that they felt their roles became too much of a caricature and that this was not helpful for learning (box 6, quotation 1-3).

\section{Theme 4: positive and negative factors in the simulation}

The statements from participants about positive and negative factors were not related to the ISS or OSS setting but rather to other factors, which are presented in subthemes $4 \mathrm{a}-4 \mathrm{e}$.

\section{Subtheme 4a: practical organisation of the simulation}

Some of the important positive factors mentioned that contributed to a realistic simulation were wearing an ordinary uniform, working with a patient (actress), and using an appropriate full-scale manikin. The researchers who observed the simulations (JLS, LEN, HMM) and the instructors (CKA, BWP) observed examples of the participants comforting the actress and the manikin, touching them gently, which exemplifies the level of authenticity. Participants stated, for example that they were not always aware of whether it was an actress or a manikin, which also supports the interpretation that the level of authenticity experienced was high. These observations were similar for ISS and OSS participants (box 7, quotations 1-2).

A recurring topic in the focus groups was phones and call procedures. During ISS and OSS participants were given a list of telephone numbers but found that calling numbers other than the ones they were used to in the clinical setting was difficult and caused confusion. For example, they called the wrong number, forgot to call staff members, called in the wrong order or phones were disconnected. ISS and OSS participants described the provided list of telephone numbers, which failed to give the intended authenticity and had the opposite effect, as a disruptive element that added negatively to 
Table 1 Distribution of recruited healthcare professional groups and dropout after recruitment in the four focus groups and baseline characteristics of participants in in situ simulations (ISS) and off-site simulation (OSS)

\begin{tabular}{|c|c|c|c|c|c|c|c|}
\hline & Recruited & Participated & $\begin{array}{l}\text { Mean age } \\
\text { (minimum- } \\
\text { maximum) }\end{array}$ & $\begin{array}{l}\text { Mean years of } \\
\text { obstetric } \\
\text { work experience } \\
\text { (minimum-maximum) }\end{array}$ & $\begin{array}{l}\text { Healthcare professional } \\
\text { groups }\end{array}$ & $\begin{array}{l}\text { Previous simulation experiences } \\
\text { No experience/simple simulation/ } \\
\text { full-scale simulation }\end{array}$ & ISS/OSS \\
\hline Focus group 1 & 6 & 6 & $44(34-55)$ & $10(2-16)$ & $\begin{array}{l}1 \text { midwife } \\
1 \text { specialised midwife } \\
2 \text { consultant obstetricians } \\
1 \text { nurse anaesthetist } \\
1 \text { trainee anaesthesiologist }\end{array}$ & $0 / 4 / 2$ & $3 / 3$ \\
\hline Focus group 2 & 7 & 7 & $50(36-64)$ & $17(1-39)$ & $\begin{array}{l}1 \text { midwife } \\
1 \text { specialised midwife } \\
1 \text { trainee obstetrician } \\
2 \text { consultant obstetricians } \\
1 \text { operating theatre nurse } \\
1 \text { trainee anaesthesiologist }\end{array}$ & $1 / 5 / 1$ & $5 / 2$ \\
\hline Focus group 3 & 7 & 7 & $42(31-62)$ & $12(2-38)$ & $\begin{array}{l}1 \text { midwife } \\
1 \text { specialised midwife } \\
1 \text { trainee obstetrician } \\
1 \text { consultant obstetrician } \\
3 \text { trainee } \\
\text { anaesthesiologists }\end{array}$ & $0 / 3 / 4$ & $2 / 5$ \\
\hline Focus group 4 & 8 & 5 & $46(39-54)$ & $14(2-26)$ & $\begin{array}{l}2 \text { auxiliary nurses } \\
1 \text { specialised midwife } \\
1 \text { trainee anaesthesiologist } \\
1 \text { consultant obstetrician }\end{array}$ & $0 / 4 / 1$ & $2 / 3$ \\
\hline $\begin{array}{l}\text { Did not show up due to clinical } \\
\text { duties or illness }\end{array}$ & 3 & & & & $\begin{array}{l}3 \text { cancellations } \\
\text { (all focus group 4): } \\
1 \text { consultant } \\
\text { anaesthesiologist } \\
1 \text { nurse anaesthetist } \\
1 \text { trainee obstetrician }\end{array}$ & & \\
\hline $\begin{array}{l}\text { Recruited but a scheduling issue } \\
\text { precluded participation }\end{array}$ & 3 & & & & 3 midwives & & \\
\hline Total & 31 & 25 & $45(31-64)$ & $13(1-39)$ & 31 & $1 / 16 / 8$ & $12 / 13$ \\
\hline
\end{tabular}


Box 2 Units of meaning derived from the interview guide and from repeatedly reading and discussing transcripts from the focus groups
- In situ versus off-site
- Expectations for the simulation
- Expected benefits
Realisme in the simulation
- Significance of setting
- Significance of the manikin
- Significance of sounds
- Tempo
Identifying oneself with the simulation
- Multidisciplinary training
- Training in own role and the role of others
- Authentic roles
- Routines
- Implication for practice
- Debriefing
Performance
Authenticity

the artificiality of the simulation. This was mentioned by both ISS and OSS participants (box 7, quotations 3).

\section{Subtheme 4b: cases in simulation scenario}

The ability of the cases to contribute to a realistic simulation was discussed. The participants had different approaches, some arguing for the necessity of highly realistic cases in simulation, where others saw this as less important, arguing that it did not matter if cases were artificial. These discussions were not related to ISS or OSS. Some participants emphasised the relief they felt because the simulated patient, that was, the actress or manikin, was not actually in real danger, which thus contributed to creating a comfortable setting for learning. Others argued that they would like to have experienced a more complex, infrequent clinical scenario because they believed that would have encouraged greater learning (box 7, quotations 4).

\section{Subtheme 4c: reversed hierarchies}

Challenges to traditional professional hierarchies were a central aspect of the negative experiences of some

\section{Box 3 Themes and subthemes}

1. Initial participant expectations for in situ and off-site simulation

2. Importance of simulation site

3. Preference for simulation in authentic roles in own workplace

4. Positive and negative factors in simulation

A. Practical organisation of the simulation

B. Cases in simulation scenario

C. Reversed hierarchies

D. Involvement in simulation

E. Debriefing

5. Individual and team learning

6. Suggested organisational changes
Box 4 Theme 1: Initial participant expectations concerning in situ and off-site simulation as illustrated by quotations

1. In the beginning I was excited about whether I would be in situ or off-site. I don't really know which one I would have preferred. In a way, in situ because then you know where everything is. But the other way would be a challenge. I thought that getting a grip on the room, which was quite different, happened fast, you very quickly get an impression of what was where [....] Even though it was an off-site simulation, everyone was aware of each other, of whether there was something that needed to be done that you could do. I think it was actually pretty exciting. I thought, who knows how l'll react? Maybe it wouldn't get my adrenalin going because it wasn't the real thing. But that's not what it was like [....] (OSS participant).

2. I had absolutely no idea whether it would be in situ or off-site. Practicing in the conference room was fine. It could have also been in the hallway or somewhere else. My experience with scenario training in situ is that the artificial aspects will always be there, in contrast to a real situation. I know full well that it's scenario training and that no one is lying there bleeding to death, but I can totally get into it regardless of the surroundings [....] The same things that I work with are there. The room didn't interfere with how well I concentrated on the situation. I simply didn't give it a single thought [.... (OSS participant).

3. I didn't have very many expectations, but I hoped that I'd be able to do in situ training because I thought it would be the most educational. But I have to agree with you [another participant] about that, because I participated in off-site training and when I left, l'd learned a lot anyway. Distancing yourself a bit from everyday life makes you even more aware that you're in fact practicing communicating. It might perhaps even be a tad easier to remember that you're practicing in that situation. I didn't think it was a disadvantage. Of course it's artificial, but I'm not sure that that has a negative impact (OSS participant).

Box 5 Theme 2: Importance of simulation site as illustrated by quotations

1. Maybe we ended up not talking about other things because we were on the third floor [OSS setting]. But there were, for example, some ordinary practical things that didn't go so well [....], but there are of course some things that you more or less do on autopilot and in the correct order when you're in your everyday surroundings (OSS participant).

2. [....] But for me, it wasn't all that different from working at another department, for example, working at the trauma centre. I'm pretty used to being in lots of different places and just using what's available. So it didn't really bother me to be in a strange place $[. . .$.$] (OSS participant).$

3. It matters where things are, if the room is different, things aren't in their usual place. I was off-site and we were on top of each other in an on-call room and couldn't really access things. We would've been much more on the ball in a delivery room (OSS participant). 
Box 6 Theme 3: Preference for simulation in authentic roles in own workplace as illustrated by quotations

1. [....] But I was looking forward to being with the professionals I work with on a daily basis. Because we play different roles in anaesthesiology [....] (ISS participant).

2. [....] It's more important that it's the right professionals. Because that hasn't been the case with the other simulations we've had. Then it's of course also important that it's the right place. So you're able to find where things are [....] The people are the most important and then perhaps the place (ISS participants).

3. [....] If you have to play other roles it becomes too much of a caricature. You don't really feel at home in the role [....] It's not just you. It's also the others-you might end up giggling a bit because you're taking on another role (OSS participants).

participants. Some participants said that when the instructors or participants asked a junior doctor to take on the role of team leader it negatively influenced the simulation and their involvement in the simulation. Reversed hierarchies occurred in both ISS and OSS (box 7, quotation 5).

\section{Subtheme 4d: involvement in simulation}

Participants thought that it was disruptive if participants or facilitators laughed, giggled or joked during the simulation as this behaviour influenced how seriously they became involved in performing the simulation, which in turn affected their learning outcome negatively. This was the case for both ISS and OSS (box 7, quotation 6).

\section{Subtheme 4e: debriefing}

ISS and OSS participants viewed debriefings as a central, exceedingly positive factor for ensuring learning. During the focus groups participants talked about what they learned and described how the simulation, followed by a debriefing, encouraged them to see their own healthcare group as part of an entire team. The participants stressed the importance of the debriefing process to ensure learning and to facilitate the transfer of that learning to clinical practice. Some of the participants even saw the focus groups as an extra debriefing. The participants also indicated that they would like to see debriefing applied in everyday work situations (box 7, quotations 7-9).

\section{Theme 5: individual and team learning}

The participants stated that their interprofessional communication, collaboration and teamwork skills had improved greatly. Focus group discussions showed that ISS and OSS offered participants the opportunity to gain new perspectives on their own work practices and areas of responsibility, as well as those of their colleagues. They gained a new understanding and respect for the efforts of other team members. Some people expressed a new understanding of why other team members did not have
Box 7 Theme 4: Positive and negative factors in the simulation as illustrated by quotations

Subtheme 4a: Practical organisation of the simulation

1. We were asked to show up dressed for work, which helps set the tone that this is realistic training [...] We were given phones so that we could call the right people [....] And there was a manikin in the bed that looked like a patient. The lower part was a manikin, but there was also a live model [actress] in the bed. That worked really well. And there was blood on the sheet and the pads were heavy. This made it [seem quite realistic] (ISS participant).

2. With regard to the manikin, I have a hard time remembering when it was a manikin and when it was a patient. It must mean that it's close to reality when you can't tell the difference (ISS participant).

3. [....] There were also some OP personnel that didn't get called. The phones were generally a mess. Which is probably why some people thought it was a bit more baffling (ISS participant).

Subtheme 4b: Cases in simulation scenario

4. [....] This time I was kind a expecting [....] it to go crazy! practically expected them [the actress and the manikin] to die. So I was a bit disappointed that it didn't involve more than that. I really thought that we'd have to go through everything, that we'd have to use HELLP and DIC and who knows what else. Which means that every time we stopped, I thought, but we just got started?! Things were in fact pretty acute and it looked like more, but it's actually very, very rare that things run the entire gamut. It's just that this is what I was mentally prepared for (ISS participant).

Subtheme 4c: Reversed hierarchies

5. [....] Two obstetricians in our session had a secret agreement that we didn't know anything about. They had set up a training situation within the training situation that the attending physician wouldn't respond. The trainee obstetrician was supposed to be in charge. They didn't tell anyone, which created a lot of confusion. At least for me because I talked to the attending senior obstetrician when I came in [...] it was a muddle [....] (ISS participant). Subtheme 4d: Involvement in simulation

6. I think that throwing yourself into things is absolutely essential to learn something. You have to be willing to play the game that's being played. Because sometimes you meet people who refuse to do that. And you expose yourself when you play a role -will I know what to do? What if I say something wrong? But if people hold back, are too inhibited and start to giggle, then the whole thing's a wash. It's really important that people give it their best shot. That's nearly the most important (ISS participant).

Subtheme 4e: Debriefing

7. It's [debriefing] still really on my mind and it was also an eyeopener for me to see how other professionals work. During the debriefing various tasks were explained that I wasn't totally sure about (OSS participant).

8. But then you take the time afterwards [at the debriefing] to break it down and get input from other groups. And you really get a better understanding of each other and where misunderstandings arise [....] (OSS participant).

9. I think that I often experience situations [in clinical practice] where we need to talk things through so we can do better next time. The problem is that there isn't time for that. During training, time is set aside for debriefing and that's wonderful. It would be great if we had time to do that on a daily basis (ISS participant). 
Box 8 Theme 5: Individual and team learning as illustrated by quotations

1. [....] The day after we had something acute at OP theatre and three of us had participated ... which means we knew each other much better [....] It was a nice situation [....] The atmosphere is much friendlier and more pleasant (OSS participant).

2. [....] it occurred to me along the way, $[\ldots .$.$] something that I$ might have let frustrate me on a daily basis. It's that a team consists of many small subprocesses. And you know what the others are doing, but not in any detail (ISS participant).

3. It dawned on me how differently we hear what's being said in the OP theatre. How the anaesthesiologist hears anaesthesia things and the obstetrician hears the midwife (OSS participant).

4. Once again this just shows that you have to talk to people, look at them, say their names, ask them to do something and then note whether they've actually understood. Because that's the only way that we can work together as a team. We bury ourselves in our own tasks (OSS participant).

time for the tasks they previously had expected them to carry out. The simulation process can thus be seen as a way of crossing professional boundaries. Participants stated that the simulation process reminded them of their own and colleagues' roles as important contributors to the entire team (box 8, quotations 1-3).

\section{Theme 6: suggested organisational changes}

The participants discussed the opportunities available for changing some everyday organisational practices and routines based on experiences from the simulation. Most of the learning points were mentioned by both ISS and OSS participants, for example communication, cooperation, teamwork, situations with unclear responsibility, feedback, a lack of general observation forms and a lack of specific observation forms, for example, postpartum haemorrhage. Some issues were only mentioned by ISS participants, such as where operation caps were located or messy corridors, which complicated the transport of beds in emergency situations and poor access to some medicines. These discussions indicate what kind of information is required to promote more practical organisational learning (box 9, quotation 1).

\section{DISCUSSION}

Our analysis indicates that authenticity in all aspects of simulation is important and that the physical setting in simulations was of less significance, indicating that OSS is just as useful if other elements of authenticity in the simulation are respected. ISS played a role at the system level and the focus group provided information pointing toward possible organisational changes. For individual and team learning, however, ISS and OSS seemed to contribute equally. Findings in the randomised controlled trial support these conclusions. ${ }^{16}$
Box 9 Theme 6: Suggested organisational changes as illustrated by quotations

1. We couldn't get the bed out the door because a porter had put a bed in the way and they were in the middle of moving a bunch of cabinets. We had to spend a lot of time moving the bed out of the delivery room. So there were lots of times where you thought, this is just unbelievable (ISS participant).

Viewed straight forwardly the context is just the setting, but the concept of context can be expanded to also include the physical, semantic and commitment context. $^{33}$ One of the arguments in favour of ISS is the contextual similarity to the context for working. 783435 Learning in context is a highly discussed topic in medical education. ${ }^{2} 1236$ Learning is said to be better recalled when the learning environment resembles the retrieval environment. $^{12} 14{ }^{15}$ Whether this traditional finding $^{37}$ can be generalised to medical education is debated and empirical findings increasingly question it. $^{10263336}$ In medical education the context may be physical, as in this study regarding the physical surroundings in ISS versus OSS. ${ }^{12} 33$ Physical surroundings or context appear to be parallel to the aspect of fidelity described as physical, that is, the degree to which the simulator resembles the appearance and perception of the real system. ${ }^{26}{ }^{38}$ Conclusions from the present focus groups indicate that healthcare professionals think that the physical context and physical fidelity of ISS and OSS were not the most important aspects for learning.

This also indicates that the semantic context, which reflects how well the context contributes to the learning task, and the commitment context, which reflects motivation and responsibility, are important aspects distinguishable from the physical context. ${ }^{33}$ The semantic and commitment dimensions of context resemble the psychological fidelity dimension, that is, the degree to which the trainee perceives the simulation to be an authentic surrogate for the task being trained. ${ }^{26}{ }^{38}$ Factors in ISS and OSS, such as problems with practical organisation, case scenarios, changes in hierarchies and engagement were considered important elements in the simulations. These factors were related to interaction between participants in the simulation, but they were not related to the physical ISS or OSS setting, which is why they appear to better represent a more complex perception of context that includes semantic and commitment elements and that can also be viewed as a part of the psychological fidelity.

The participants in the focus groups highlighted the importance of participating in authentic teams in their own roles as healthcare professionals. The interview guide (box 1) encouraged participants to compare their current ISS and OSS experiences with previous simulation experiences. The focus groups had a clearly preferred simulation in authentic roles in their own workplace. The concept of training in other roles so- 
called cross training, is recommended in the simulation literature and considered a strategy for simulation-based medical education. ${ }^{39}$ Cross training is defined as "an instructional strategy in which each team member is trained in the duties of his or her teammates". ${ }^{40}$ It is argued that if all team members have a shared understanding of other people's roles then the risk of making errors decreases. ${ }^{41}$ Although there are examples of empirical studies that address cross training, they only comprise small teams in an experimental laboratory setting and mainly use computer-based simulation, and there are no medical studies that involve multiprofessional teams. ${ }^{40-42}$ Since the simulations in the present study were complex and included teams of 10 from 6 different healthcare professional groups, we concluded that the authenticity and psychological fidelity would have been damaged by changing professional roles. This finding on cross training, however, will need to be investigated in future studies using outcomes other than the perceptions of participants.

The current concept of fidelity is under debate $^{10} 264344$ and may not be adequate enough to explain the fidelity practiced in interprofessional simulation. The simulation literature tends to overlook the importance of social practice, ${ }^{44}$ hierarchy, power relations and other factors affecting interprofessional teamwork. ${ }^{45}$ The concept sociological fidelity has thus been introduced and aims to enhance the quality of interprofessional simulation and to improve its transferability to interprofessional practice. ${ }^{45} 46$

The interprofessional teams in our study were highly appreciated by the participants in the focus groups and can have contributed positively to the so-called sociological fidelity. Planning simulation for interprofessional groups is challenging, especially with regard to planning and designing case scenarios that provide each profession with a significant, balanced role. ${ }^{28}{ }^{46}$ Even though we appointed a multiprofessional working committee with representatives from each healthcare group to avoid conflicts ${ }^{16}$ disagreement concerning the complexity of cases still arose.

\section{Strengths and limitations}

The present study adhered to criteria for focus groups $^{2023}$ to support the transparency and add to the credibility of the study findings from the focus groups. The study was performed in the obstetrics and anaesthesiology departments of a high-risk hospital. Its transferability $^{20}$ to other settings can be discussed, but our impression is that the findings are transferable to other emergency medical specialities. The findings from the focus groups in this study show that staff in obstetrics and anaesthesiology appear to be more familiar with working in different places, which they see as an important skill, but we cannot say whether study findings are transferable to other groups of healthcare professionals working in medical areas with less emergency work. We found a tendency that auxiliary and operating theatre nurses appeared to have a greater need for higher authenticity or fidelity of setting. These professional groups had very little or no simulation experience, and this finding is in contradiction with some of the literature finding showing that non-experts or noviceparticipants in simulation can accept a lower level of authenticity or fidelity. ${ }^{3}$

Findings in the present focus group were comparable with the results in the randomised controlled trial conducted prior to this qualitative study. ${ }^{16}$

To avoid bias only moderators who had never worked with the participants were selected. One element of the study with the potential for bias, however, was recruitment of participants for the focus groups because they were enlisted from among participants in the randomised controlled trial. ${ }^{16}$ They may have had a special interest in simulation and interprofessional activities, perhaps making them more motivated and less representative of all staff. Co-construction in the focus groups, however, meant that a broad variety of views were presented.

Half of the people in the focus groups participated in ISS and the other half in OSS. The central purpose of the focus groups was to bring out the differences in what people experienced and to enable them to co-construct and make indirect comparisons between the learning outcomes they experienced from doing either ISS or OSS. The participants also used their previous simulation experiences to mirror their new experiences. Many of the participants knew each other, which may have prevented them from openly providing sensitive information or completely expressing their opinions and feelings. The heterogeneity of the groups may have influenced the group dynamics and the potential power relationships between groups. Experienced moderators were used in the attempt to avoid this.

Another limitation was the composition of the focus groups, which did not entirely mirror the distribution of healthcare professionals during the clinical work and that some groups were under-represented.

\section{CONCLUSION}

This study presents a new finding, which is that, in the eyes of healthcare professionals, OSS can be used just as well as ISS if other authenticity elements are taken into consideration and respected. This finding needs to be confirmed in other institutions and medical specialities as well as among other kinds of healthcare professionals and participants with less experience in simulation-based learning.

Analysis of the focus groups indicates that cross training is not an optimal solution, but additional testing of the concept ${ }^{39-41}$ among larger medical teams composed of a larger variety of healthcare professionals in more complex simulations needs to be carried out to confirm and explore this conclusion further.

Findings in the present study are supported by the randomised controlled trial compared ISS to OSS conducted 
as in-house training at the hospital in rooms allocated to training. ${ }^{16}$ The results from this study on the setting of simulations adds knowledge that may be useful in the planning and decision-making process for building and rebuilding new hospitals, facilities for training and simulation centres.

The study findings were based on focus groups and on the participants' immediate perceptions. Measuring the outcome of medical education ${ }^{47}$ is a complex process, which is why including long-term feedback from participants in future studies, as well as the effect on outcome in patient care practices or patient outcomes would be useful.

This study concludes that the psychological and socalled sociological fidelity elements of the simulation are important and that the physical context of the simulation is less important. Based on findings from the focus groups, OSS can be employed if other authenticity elements are considered and respected.

\author{
Author affiliations \\ ${ }^{1} J u l i a n e$ Marie Centre for Children, Women and Reproduction, Rigshospitalet, \\ University of Copenhagen, Copenhagen, Denmark \\ ${ }^{2}$ Danish Institute for Local and Regional Government Research (KORA), \\ Copenhagen, Denmark \\ ${ }^{3}$ Department of Anaesthesiology, Juliane Marie Centre for Children, Women \\ and Reproduction, Rigshospitalet, University of Copenhagen, Copenhagen, \\ Denmark \\ ${ }^{4}$ Department of Obstetrics, Juliane Marie Centre for Children, Women and \\ Reproduction, Rigshospitalet, University of Copenhagen, Copenhagen, \\ Denmark \\ ${ }^{5}$ The Research Unit Women's and Children's Health, Juliane Marie Centre for \\ Children, Women and Reproduction, Rigshospitalet, University of \\ Copenhagen, Copenhagen, Denmark \\ ${ }^{6}$ Department of Educational Development and Research, Faculty of Health, \\ Medicine and Life Sciences, Maastricht University, Maastricht, The \\ Netherlands
}

Acknowledgements The authors would like to thank the doctors, midwives and nurses who took part in the working committee that planned the intervention, specifically midwife Pernille Langhoff-Roos (Obstetrics Department, Rigshospitalet, University of Copenhagen) for assisting in the recruitment of participants. The authors would also like to thank copy editor and translator Nancy Aaen for revising the manuscript and for translating quotations from the focus groups from Danish to English.

Contributors JLS created the idea for this study, aided by $\mathrm{HK}^{\dagger}$. All authors, but specifically JLS, LEN and HMM, contributed to the study's design. $\mathrm{BO}$ and CVdV were supervisors. JLS, assisted by BO, was responsible for acquiring funding. JLS, LEN and HMM performed the initial data processing. All authors, except $\mathrm{HK}^{\dagger}$ provided critical review of the paper and approved the final manuscript.

Funding The non-profit Danish Regions Development and Research Foundation provided the majority of the funding for the randomised controlled trial $^{16}$ and this study, while two additional non-profit funds, the Laerdal Foundation for Acute Medicine and the Aase and Ejnar Danielsen Foundation, provided the remaining funding. None of the foundations had a role in the design or conduct of the study.

Competing interests None declared.

Ethics approval The Regional Ethics Committee (protocol no. H-2-2012-155) and the Danish Data Protection Agency (no. 2007-58-0015) approved the study. Participants gave written informed consent. Participants were assured that their personal data would remain anonymous during reporting and were asked to respect the confidentiality of everything said in the focus group.

Provenance and peer review Not commissioned; externally peer reviewed.
Data sharing statement No additional data are available.

Open Access This is an Open Access article distributed in accordance with the Creative Commons Attribution Non Commercial (CC BY-NC 4.0) license, which permits others to distribute, remix, adapt, build upon this work noncommercially, and license their derivative works on different terms, provided the original work is properly cited and the use is non-commercial. See: http:// creativecommons.org/licenses/by-nc/4.0/

\section{REFERENCES}

1. Issenberg SB, McGaghie WC, Petrusa ER, et al. Features and uses of high-fidelity medical simulations that lead to effective learning: a BEME systematic review. Med Teach 2005;27:10-28.

2. McGaghie WC, Issenberg SB, Petrusa ER, et al. A critical review of simulation-based medical education research: 2003-2009. Med Educ 2010:44:50-63.

3. Motola I, Devine LA, Chung HS, et al. Simulation in healthcare education: a best evidence practical guide. AMEE Guide No. 82 Med Teach 2013;35:e1511-30.

4. McGaghie WC, Issenberg SB, Barsuk JH, et al. A critical review of simulation-based mastery learning with translational outcomes. Med Educ 2014;48:375-85.

5. Merien AE, Van der Ven J, Mol BW, et al. Multidisciplinary team training in a simulation setting for acute obstetric emergencies: a systematic review. Obstet Gynecol 2010;115:1021-31.

6. Riley W, Davis S, Miller KM, et al. Detecting breaches in defensive barriers using in situ simulation for obstetric emergencies. Qual Saf Health Care 2010;19(Suppl 3):i53-6.

7. Walker ST, Sevdalis N, McKay A, et al. Unannounced in situ simulations: integrating training and clinical practice. BMJ Qual Saf 2013;22:453-8.

8. Rosen MA, Hunt EA, Pronovost PJ, et al. In situ simulation in continuing education for the health care professions: a systematic review. J Contin Educ Health Prof 2012;32:243-54.

9. Patterson MD, Geis GL, Falcone RA, et al. In situ simulation: detection of safety threats and teamwork training in a high risk emergency department. BMJ Qual Saf 2013;22:468-77.

10. Grierson LE. Information processing, specificity of practice, and the transfer of learning: considerations for reconsidering fidelity. Adv Health Sci Educ Theory Pract 2014;19:281-9.

11. Kneebone RL, Kidd J, Nestel D, et al. Blurring the boundaries: scenario-based simulation in a clinical setting. Med Educ 2005;39:580-7.

12. Teunissen PW, Wilkinson TJ. Learning and teaching in workplaces. In: Dornan T, Mann K, Scherpbier A, Spencer J, eds. Medical education: theory and practice. Edinburgh, London, New York, Oxford, Philadelphia, St Louis, Sydney, Toronto: Churchill Livingstone Elsevier, 2011:193-209.

13. Teteris $\mathrm{E}$, Fraser $\mathrm{K}$, Wright $\mathrm{B}$, et al. Does training learners on simulators benefit real patients? Adv Health Sci Educ Theory Pract 2012:17:137-44.

14. Durning SJ, Artino AR Jr, Pangaro LN, et al. Perspective: redefining context in the clinical encounter: implications for research and training in medical education. Acad Med 2010;85:894-901.

15. Durning SJ, Artino AR. Situativity theory: a perspective on how participants and the environment can interact: AMEE Guide no. 52. Med Teach 2011;33:188-99.

16. Sørensen JL, van der Vleuten C, Rosthøj S, et al. Simulation-based multiprofessional obstetric anaesthesia training conducted in situ versus off-site leads to similar individual and team outcomes: a randomised educational trial. BMJ Open 2015;5:e008344

17. Cook DA, Bordage G, Schmidt HG. Description, justification and clarification: a framework for classifying the purposes of research in medical education. Med Educ 2008;42:128-33.

18. Lewin S, Glenton C, Oxman AD. Use of qualitative methods alongside randomised controlled trials of complex healthcare interventions: methodological study. BMJ 2009;339:b3496.

19. Kitzinger J. Qualitative research. Introducing focus groups. BMJ 1995;311:299-302.

20. Stalmeijer RE, Mcnaughton N, Van Mook WN. Using focus groups in medical education research: AMEE Guide No. 91. Med Teach 2014;36:923-39.

21. Kuper A, Reeves S, Levinson W. An introduction to reading and appraising qualitative research. BMJ 2008;337:a288.

22. Malterud K. Qualitative research: standards, challenges, and guidelines. Lancet 2001;358:483-8.

23. Tong A, Sainsbury $P$, Craig J. Consolidated criteria for reporting qualitative research (COREQ): a 32-item checklist for interviews and focus groups. Int J Qual Health Care 2007;19:349-57. 
24. Fraenkal JR, Wallen NE, Hyun $\mathrm{HH}$. Observation and interviewing. In: Fraenkal JR, Wallen NE, Hyun $\mathrm{HH}$, eds. How to design and evaluate research in education. 8th edn. New York: McGraw-Hill, 2012:444-76.

25. Rudolph JW, Simon R, Dufresne RL, et al. There's no such thing as "nonjudgmental" debriefing: a theory and method for debriefing with good judgment. Simul Healthc 2006;1:49-55.

26. Norman G, Dore K, Grierson L. The minimal relationship between simulation fidelity and transfer of learning. Med Educ 2012;46:636-47.

27. Sørensen JL, Lokkegaard E, Johansen M, et al. The implementation and evaluation of a mandatory multi-professional obstetric skills training program. Acta Obstet Gynecol Scand 2009;88:1107-17.

28. Sørensen JL, Lottrup P, Vleuten van der C, et al. Unannounced in situ simulation of obstetric emergencies: staff perceptions and organisational impact. Postgrad Med J 2014;90:622-9.

29. Hsieh HF, Shannon SE. Three approaches to qualitative content analysis. Qual Health Res 2005:15:1277-88.

30. Graneheim UH, Lundman B. Qualitative content analysis in nursing research: concepts, procedures and measures to achieve trustworthiness. Nurse Educ Today 2003:24:105-12.

31. Fraenkal JR, Wallen NE, Hyun HH. Content analysis. In: Fraenkal $\mathrm{JR}$, Wallen $\mathrm{NE}$, Hyun $\mathrm{HH}$, eds. How to design and evaluate research in education. 8th edn. New York: McGraw-Hill, 2012:477-504.

32. Malterud K. Systematic text condensation: a strategy for qualitative analysis. Scand J Public Health 2012;40:795-805.

33. Koens F, Mann KV, Custers EJ, et al. Analysing the concept of context in medical education. Med Educ 2005;39:1243-9.

34. Patterson MD, Geis GL, Lemaster T, et al. Impact of multidisciplinary simulation-based training on patient safety in a paediatric emergency department. BMJ Qual Saf 2013;22:383-93.

35. Raemer DB. Ignaz semmelweis redux? Simul Healthc 2014;9:153-5.
36. Koens F, Ten Cate OT, Custers EJ. Context-dependent memory in a meaningful environment for medical education: in the classroom and at the bedside. Adv Health Sci Educ Theory Pract 2003;8:155-65.

37. Godden DR, Baddeley AD. Context-dependent memory in two natural environments: on land and underwater. Br J Psychol 1975;66:325-31.

38. Beaubien JM, Baker DP. The use of simulation for training teamwork skills in health care: how low can you go? Qual Saf Health Care 2004;13(Suppl 1):i51-6.

39. Wilson KA, Burke CS, Priest HA, et al. Promoting health care safety through training high reliability teams. Qual Saf Health Care 2005;14:303-9.

40. Volpe CE, Cannon-Bowers JA, Salas E, et al. The impact of cross-training on team functioning: an empirical investigation. Hum Factors 1996;38:87-100.

41. Marks MA, Sabella MJ, Burke CS, et al. The impact of cross-training on team effectiveness. J Appl Psychol 2002;87:3-13.

42. Gorman JC, Cooke NJ, Amazeen PG. Training adaptive teams. Hum Factors 2010;52:295-307.

43. Hamstra SJ, Brydges R, Hatala R, et al. Reconsidering fidelity in simulation-based training. Acad Med 2014;89:387-92.

44. Dieckmann P, Gaba D, Rall M. Deepening the theoretical foundations of patient simulation as social practice. Simul Healthc 2007;2:183-93.

45. Sharma S, Boet S, Kitto $S$, et al. Interprofessional simulated learning: the need for 'sociological fidelity'. J Interprof Care 2011;25:81-3.

46. Boet S, Bould MD, Layat BC, et al. Twelve tips for a successful interprofessional team-based high-fidelity simulation education session. Med Teach 2014;36:853-7.

47. Cook DA, West CP. Perspective: reconsidering the focus on "outcomes research" in medical education: a cautionary note. Acad Med 2013;88:162-7. 